\title{
Sargassum, Gracilaria and Ulva Exhibit Positive Antimicrobial Activity against Human Pathogens
}

\author{
Amrit Kumar Mishra ${ }^{1,2}$ \\ ${ }^{1}$ Department of Ocean Studies and Marine Biology, School of Life Sciences, Pondicherry University, Brookshabad Campus, \\ Portbalir, Andaman and Nicobar Islands, India \\ ${ }^{2}$ Marine Biology and Ecology Research Centre, Davy Building, University of Plymouth, Plymouth, UK \\ Email: amritkumarishra@gmail.com
}

How to cite this paper: Mishra, A.K. (2018) Sargassum, Gracilaria and Ulva Exhibit Positive Antimicrobial Activity against $\mathrm{Hu}-$ man Pathogens. Open Access Library Journal, 5: e4258.

https://doi.org/10.4236/oalib.1104258

Received: December 15, 2017

Accepted: January 8, 2018

Published: January 11, 2018

Copyright $\odot 2018$ by author and Open Access Library Inc.

This work is licensed under the Creative Commons Attribution International License (CC BY 4.0).

http://creativecommons.org/licenses/by/4.0/

\section{(c) (i) Open Access}

\begin{abstract}
Bacterial resistance to pharmaceutical drugs is on rise, which emphasizes the need for screening of new drugs from natural resources. Seaweeds from the marine ecosystem are important source of bioactive compounds making them one of the major subjects for screening of various pharmaceutical drugs. So here, we assessed the bacterial growth inhibitory functions of four seaweeds Sargassum wightii, Gracillaria edulis, G. corticata and Ulva lactuca of Andaman Sea and Bay of Bengal, India respectively against three pathogens Pseudomonas aeruginosa, Eischeira coli and Staphylococcus aureus. Solvent extraction of four seaweeds was performed using 70\% methanol, ethanol and ethyl acetate. Agar well diffusion method was used to test the bioactivity of seaweeds against pathogens. $S$. wightii, G. edulis and $U$. lactuca were observed with better solvent extracts compared to G. corticata. Methanol extract of $S$. wightii was observed with the highest $(29.0 \pm 1.22)$ zone of inhibition (ZOI) and ethyl acetate extract of $U$. lactuca was observed with the lowest ZOI $(5.0 \pm 0.0)$ against $S$. aureus. Butanol extract of $S$. wightii was observed with the highest ZOI $(14.0 \pm 0.83)$ against $P$. aeruginosa, whereas $G$. edulis methanol extract and $U$. lactuca ethyl-acetate extract were observed with the lowest ZOI $(6.0 \pm 0.0)$. For $E$. coli, butanol and methanol extracts of $G$. edulis and $U$. lactuca showed the highest $(12.0 \pm 0.54)$ and the lowest $(6.0 \pm 0.0)$. Our preliminary results suggest bioactivity of $S$. wightii, G. edulis and $U$. lactuca showed positive results. Further biochemical characterization of $S$. wightii should be carried out for potential bioactive compounds against human pathogens. Our results suggest bioactive compounds from seaweeds can be used as pharmaceutical drugs.
\end{abstract}

\section{Subject Areas}

Ecology, Marine Biology, Microbiology 


\section{Keywords}

Bioactive Compounds, Antibiotics, Human Pathogens, Indian Ocean, Solvent Extraction

\section{Introduction}

Antibiotics resistance is one of the biggest threats to global food security, global health and development of mankind [1]. To overcome the resistance of bacterial pathogens, continuous screening and development of potential new drugs from natural products are necessary. Natural products from marine ecosystems are diverse source of bioactive compounds due to the harsh environmental conditions in which the organisms survive [2]. In these environments, the organisms produce secondary metabolites to overcome the surrounding competition for food, habitat, to escape predation, to maintain homeostasis in the environment and to defend themselves against grazing and biofouling organisms [3] [4]. These secondary metabolites are a continuous source of bioactive compounds ranging from microalgae, coral reefs, sponges, fishes to macroalgae or seaweeds [4] [5].

The coastal zone of India is diverse and harbours various kinds of seaweeds in the intertidal region or estuarine zone of coastal ecosystems [5]. These marine macrophytes or seaweeds are multicellular algae categorised into three main groups of Chlorophyceae (Green algae), Phaeophyceae (Brown algae) and Rhodopycae (Red algae) based on their colored pigments [6] [7]. Seaweeds from all three groups are used in various industries for agar production, used in agriculture as fertilizer, food and fodder and medicines [8] [9]. These seaweeds possess various sources of secondary metabolites that possess antimicrobial properties [10]. These secondary metabolites comprise of diverse type of compounds [4], for example, polysaccharides and derived oligosaccharides like alginates, carrageenans, galactans, laminarians, fucans and ulvans [11] [12], lipids, fatty acids and sterols like phospholipids, glycolipids, carboxylic acids, fucosterol [13], phenolic compounds [14], pigments like carotenoids [15] and other compounds like lectins [16], alkaloids [17] and terpenes [18]. Presence of these various compounds makes the seaweeds valuable in pharmaceutical industries, where they have been largely screened in drug development for antibacterial, antifungal [19] [20], antiviral [21] and antitumor activities [22].

Studies on bioactivity of seaweeds in India have considered various solvent extraction procedures to test the antibacterial activity of seaweeds on human pathogens. For instance, five different species of Gracilaria (brown algae) of South coast of India were extracted using 10 organic solvents and five different human pathogens and only two solvents, i.e. isoamyl alcohol and chloroform were observed with antibacterial activity against all pathogens [23], whereas methanol extract of $G$. edulis from South coast of India showed maximum inhibitory against bacterial (Staphylococcus aureus, Eischeira coli and Pseudomonas 
aeruginosa) and fungal pathogens [24]. Similarly, methanol extract of only Dictyosphaeria cavernosa (green algae) was observed with antibacterial activity against $S$. aureus out of five different seaweed species of Andaman Sea screened for antibacterial activity [25], whereas green algae of Andaman Sea, Halimeda opuntia ethanol extracts showed maximum antibacterial activity against $E$. coli and $S$. aureus [26]. Ulva reticulata n-butanol extracts were effective against $E$. coli while screened for antibacterial activity [27], whereas Ulva lactuca chloroform extracts were effective against $S$. aureus, E. coli and P. aeruginosa [28] [29]. However, methanol extracts of both $U$. reticulata and $U$. lactuca were effective against human pathogens [30]. In case of Sargassum wightii methanol extracts were effective against $S$. aureus [31] and against $E$. coli, and P. aeruginosa [32], whereas ethyl acetate extracts of $S$. wightii were only effective against Bacillus subtilis [33].

However, considering the growing need for new source of bioactive compounds to fight microbial resistance, here in our research we are screening a combination of red, green and brown algae against human pathogens via solvent extraction procedures. Solvent extracts of Sargassum wightii (Brown algae) and Gracilaria edulis (Red algae) of Andaman Sea and G. corticata (Red algae) and Ulva lactuca (Green algae) of South-east coast of Tamilnadu, India against three human pathogens (Pseudomonas aureus, Eischeira coli and Staphylococcus aeruginosa) to understand the bioactivity of these seaweeds against similar pathogens.

\section{Methods}

\subsection{Seaweed Collection}

Seaweeds, Sargassum wightii and Gracillaria edulis samples were collected from the islands of Andaman and Nicobar in Andaman Sea, India. Samples of Ulva lactuca and Gracillaria corticata were collected from the southeast coast of Tamilnadu in Bay of Bengal, India. Identification of seaweeds was done at the Department of Ocean Studies and Marine Biology, Portblair, Andaman and Nicobar Islands. After collection all the seaweed samples were washed with distilled water thrice to remove the epiphytes and debris attached to the blades and dried in shade. Sun drying or hot air drying was avoided to save the volatile compounds that escape at higher than room temperature.

\subsection{Solvent Extraction}

Dried seaweed blades of approximately 2 gm were crushed in a mortar and were place in culture bottles along with $25 \mathrm{ml}$ of solvents for extraction. Three solvents were used, i.e. methanol, butanol and ethyl acetate for each seaweed sample. These culture bottles were covered with aluminium foils and were kept in normal room temperature in a shaker $(50-70 \mathrm{rpm})$ for two days for the extraction of bioactive compounds by the solvent. Distillation process was used for solvent extraction. 


\subsection{Pathogenic Organisms and Biochemical Characterization}

The pathogenic organisms Pseudomonas aureus, Eischeira coli and Staphylococcus aeruginosa were selected from clinical samples. The collected samples were incubated in nutrient broth and incubated for 24 hours at $37^{\circ} \mathrm{C}$. After the initial incubation the organisms were cultured again in nutrient agar medium and incubated for another 24 hours at $37^{\circ} \mathrm{C}$ to get isolated pure cultures. Gram staining was performed for these isolates to confirm, if they are gram positive or negative. The morphologically identified organisms were then grown on selective media such as Eosin Methylene Blue (EMB) agar, starch agar, Mannitol salt agar and blood agar. To confirm the specificity of each bacteria used, the selectively grown isolates were characterized by various biochemical tests. After confirmation through various biochemical tests the microbes were isolated and cultured in nutrient agar plates for maintaining pure culture and used for antimicrobial activity tests.

\subsection{Determination of Antimicrobial Activity}

Antimicrobial activity of seaweed samples was determined by agar diffusion method. Five identical colonies of E. coli, S. aureus and P. aeruginosa were lifted with sterile loop from each pure culture agar plates and transferred into a sterile tube containing $5 \mathrm{ml}$ of nutrient broth. These tubes were incubated at $37^{\circ} \mathrm{C}$ for 24 hours. Then Muller Hilton (MH) agar was prepared sterilized and was poured on petri dishes and cooled. Into these sterile petri dishes with $\mathrm{MH}$ agar medium fresh cultures of microbes $(0.1 \mathrm{ml})$ were inoculated from nutrient broth. Each inoculated petri dishes were swirled to distribute the medium homogeneously and allowed to dry for 15 - 20 minutes. Wells $(n=5)$ of $7 \mathrm{~mm}$ were made into previously seeded $\mathrm{MH}$ agar plates. Each well was filled with $50 \mu \mathrm{l}$ each plant extract. Same petridishes were used as controls, where instead of plant extract $75 \%$ ethanol was used. Petri dishes were kept in room temperature around 1 hour for the seaweed extract to diffuse and then were incubated at $37^{\circ} \mathrm{C}$ for 24 hours. Subsequently, the dishes were examined for bacterial growth inhibition. The diameter of cleared zones was measured in millimetre $(\mathrm{mm})$. Transparent clear zones were considered to have bacteriostatic activity. All values are expressed as mean \pm standard deviation (SD). All values were tested for normality and standard deviation.

\section{Results}

The three solvents used for seaweed extraction showed a significant variation in their extraction capacities. The percentage of extraction for each seaweed was different for each solvent with highest extractions of seaweed being observed in ethyl-acetate followed by butanol and methanol (Table 1). In methanol and ethyl-acetate $S$. wightii showed the highest extraction, whereas in butanol $U$. lactuca extraction was highest. In all three solvents, $G$. corticata showed the lowest extraction (Table 1). 
Both $E$. coli and $P$. aeruginosa were gram negative with greenish colour where $S$. aureus was gram positive with golden yellow colour as observed from the colonies in selective growth media and gram staining procedures (Table 2). The results of various biochemical tests for the selected pathogens are presented in Table 3. Both $P$. aeruginosa and $E$. coli were showed positive results for Indole production, oxidase and nitrate reduction test, whereas $E$. coli showed positive results for catalse activity. Similarly, $S$. aureus showed positive results for Voges-Proskauer, gelatine, catalase and nitrate reduction test (Table 3 ).

Zones of inhibition (ZOI) that determine seaweeds antimicrobial activity were significantly different between for the extracted solvent and the pathogens used (Table 4). 4-fold higher ZOI was observed for $S$. wightii methanol extract $(29.0$ $\pm 1.22)$ than ethyl-acetate extract $(6.0 \pm 0.44)$ against $S$. aureus (Table 4$)$. In case of $G$. edulis both methanol and butanol extract were observed with similar ZOI range for all the three pathogens, exception was ethyl-acetate extract with only observable ZOI for $P$. aeruginosa. In $G$. corticata there were no observed ZOI for methanol extract, whereas butanol extract against $P$. aeruginosa was observed with highest ZOI. In $U$. lactuca 2-fold higher ZOI was observed for butanol extract against $P$. aeruginosa and $E$. coli than ethyl-acetate extract against $S$. aureus (Table 4). Overall the highest and lowest ZOI were observed for gram positive $S$. aureus in our results.

Table 1. Weight loss $(n=5$, Mean \pm SD) of four seaweeds during solvent extraction in Methanol (M), Butanol (B) and Ethyl acetate (EA).

\begin{tabular}{ccccc}
\hline Seaweed & Solvent & Initial weight (gm) & Final weight (gm) & Weight loss (gm) \\
\hline S. wightii & M & $2.29 \pm 0.31$ & $1.95 \pm 0.02$ & $0.33 \pm 0.05$ \\
& B & $2.28 \pm 0.04$ & $1.87 \pm 0.01$ & $0.40 \pm 0.05$ \\
G. edulis & EA & $2.25 \pm 0.01$ & $1.64 \pm 0.02$ & $0.61 \pm 0.03$ \\
& M & $2.40 \pm 0.04$ & $1.97 \pm 0.01$ & $0.42 \pm 0.04$ \\
& B & $2.14 \pm 0.02$ & $1.62 \pm 0.02$ & $0.52 \pm 0.02$ \\
G. corticata & EA & $2.20 \pm 0.03$ & $1.61 \pm 0.01$ & $0.59 \pm 0.05$ \\
& M & $2.29 \pm 0.03$ & $1.21 \pm 0.02$ & $0.07 \pm 0.03$ \\
& B & $2.40 \pm 0.04$ & $2.35 \pm 0.04$ & $0.04 \pm 0.00$ \\
U. lactuca & EA & $2.21 \pm 0.02$ & $2.18 \pm 0.01$ & $0.03 \pm 0.01$ \\
& M & $2.40 \pm 0.04$ & $2.18 \pm 0.04$ & $0.21 \pm 0.23$ \\
& B & $2.28 \pm 0.04$ & $1.77 \pm 0.03$ & $0.50 \pm 0.04$ \\
& EA & $2.40 \pm 0.04$ & $2.18 \pm 0.04$ & $0.21 \pm 0.02$ \\
\hline
\end{tabular}

Table 2. Morphological response of the pathogens during growth in selective media and Gram staining.

\begin{tabular}{cccc}
\hline Media & Observation & Pathogens & Staining results \\
\hline EMB agar & Greenish metallic sheen & E. coli & Gm - ve \\
Mannitol salt agar & Golden yellow colonies & S. aureus & $G m+v e$ \\
Centrimide agar & Green tinch & P. aeruginosa & $G m-v e$ \\
\hline
\end{tabular}


Table 3. Results of various biochemical tests of $P$. aeruginosa, $S$. aureus and E. coli. Positive $(+)$ and negative $(-)$ represent positive and negative response for biochemical tests for each pathogen.

\begin{tabular}{cccc}
\hline Test & $P$. aeruginosa & S. aureus & E. coli \\
\hline Indole & + & - & + \\
Methyl red & - & - & - \\
Voges-Proskauer & - & + & - \\
Gelatine & - & + & - \\
Catalase & - & + & + \\
Oxidase & + & - & + \\
Nitrate & + & + & + \\
Starch & - & - & - \\
Citrate & - & - & - \\
\hline
\end{tabular}

Table 4. Zone of inhibition ( $n=5$, Mean \pm SD) observed for each seaweed species with solvent extraction in Methanol (M), Butanol (B) and Ethyl acetate (EA). No zone of inhibition is represented by $(-)$.

\begin{tabular}{ccccc}
\hline Seaweed & Solvent & \multicolumn{3}{c}{ Zone of inhibition (mm) } \\
\hline \multirow{2}{*}{ S. wightii } & M & P. aeruginosa & $S$. aureus & E. coli \\
\cline { 3 - 5 } & B & $7.0 \pm 0.54$ & $29.0 \pm 1.22$ & - \\
\hline \multirow{3}{*}{ G. edulis } & EA & $9.0 \pm 0.70$ & $6.0 \pm 0.44$ & $7.0 \pm 0.44$ \\
& M & $6.0 \pm 0.54$ & $6.0 \pm 0.54$ & $6.0 \pm 0.54$ \\
G. corticata & B & $12.0 \pm 0.57$ & $13.0 \pm 0.57$ & $12.0 \pm 0.54$ \\
& EA & $11.0 \pm 0.83$ & - & - \\
U. lactuca & M & - & - & - \\
& B & $10.0 \pm 0.44$ & $9.0 \pm 0.54$ & $9.0 \pm 0.0$ \\
& EA & $7.0 \pm 0.44$ & $7.0 \pm 0.54$ & $7.0 \pm 0.0$ \\
& M & $8.0 \pm 0.44$ & $6.0 \pm 0.0$ & $6.0 \pm 0.54$ \\
& B & $12.0 \pm 0.54$ & $11.0 \pm 0.83$ & $12.0 \pm 0.83$ \\
& EA & $6.0 \pm 0.0$ & $5.0 \pm 0.0$ & $8.0 \pm 0.0$ \\
\hline
\end{tabular}

\section{Discussion}

Antimicrobial activity of $S$. wightii, G. edulis, G. corticata and U. lactuca from Andaman Sea and Bay of Bengal, India was screened against $S$. aureus, $P$. aeruginosa and E. coli through solvent extraction procedures in our studies. The extraction of seaweed bioactive compounds through solvent extracts was different due to the various nutritive and antioxidant contents of the seaweed, similar difference in extractions has been observed previously for solvent extracts of other seaweeds [34].

Methanol extract of $S$. wightii showed the highest ZOI for $S$. aureus though the weight loss in the extraction was less than butanol and ethyl acetate (Table 
1). This suggests that methanol is a better solvent for consistent extraction of bioactive compounds from brown seaweeds, which was observed previously for plants [35]. The capacity of methanol for better extraction is due to the enhancement of methanol soluble bioactive components of $S$. wightii like alkaloids, steroids, flavonoids, essential oils and biterpenoids resulting in higher number of bioactive compounds extracted from the macroalgae [36].

We observed red, green and brown seaweed possessing different levels of bioactivity when extracted through various solvents. This indicates seaweeds biochemical composition and growth stage play a major role in producing bioactive compounds that are extractable through various solvents [37]. Secondly the various solvents used are different in their chemical composition that also affects the extraction of bioactive compounds. Thirdly, the bioassay methods, geographical distribution of seaweeds and seasonal production of bioactive compounds also contribute to the efficient bioactive property of seaweeds [38].

Methanol extracts of seaweed showed the highest ZOI for bacterial pathogens, suggesting methanol as one of the better solvents than butanol and ethyl-acetate, which has been previously observed for methanol [39] [40] [41] [42]. The highest ZOI against $S$. aureus (Gram positive bacteria) in our results for methanol extract of $S$. wightii coincides with previous cases where methanol extracts provided the highest ZOI, suggesting methanol extracts of seaweeds are efficiently bioactive against Gram-positive bacteria than Gram-negative bacterial species [24] [41] [42].

In our results, ZOI formed by $S$. wightii methanol extracts against $S$. aureus was the highest, which was 2.9-fold higher than previously observed for $S$. wightii methanol extract from Mandapam [31] and agreed that methanol extract for $\mathcal{S}$. wightii against $S$. aureus was better than other solvents [42]. Though, $S$. wightii butanol and ethyl acetate extracts showed considerable bioactivity against both $S$. aureus, $P$. aeruginosa and $E$. coli in our results, $S$. wightii methanol extracts showed no bioactivity against $E$. coli, which agreed with the findings for Sargassum vulgare with no activity [44] and disagreed with observations for $S$. wightii [45]. This difference in bioactivity against E. coli for Sargassum species can be due to the different antibacterial compounds which these species harbour and their interaction with pathogens [33].

Methanol extraction of $G$. edulis in our studies formed 6-fold higher ZOI against $S$. aureus and $P$. aeruginosa and 3-fold lower ZOI against $S$. aureus than previously observed for G. edulis from Tamilnadu, India [23] [24], whereas methanol extracts of $G$. corticata showed no ZOI against $S$. aureus and $P$. aeruginosa in our results. Lower or no activity of Gracilaria species in our results can be due to the lower biomass $(2 \mathrm{mg})$ used for solvent extraction, as previous studies on $G$. corticata showed considerable antibacterial activity against $S$. aureus and $P$. aeruginosa in methanol extracts when $4-5 \mathrm{mg}$ of dried biomass is used [24] [44].

Methanol and ethyl acetate extracts of $U$. lactuca formed 2-fold lower ZOI 
against $S$. aureus in our studies, whereas for $P$. aeruginosa, the ZOI was not very different and for E. coli ZOI was almost 2-fold lower than methanol extract and similar with ethyl acetate extract, than results obtained for $U$. lactuca from South coast of India [30].

The differences in antimicrobial activity of various seaweeds analysed in our research were different, which is a result of various factors such as herbivory, light depth, nutrients and the growing environmental conditions [45]. However, our results showed that seaweeds growing in oligotrophic trophic waters of Andaman Sea have higher bioactivity than the seaweeds growing in nutrient rich waters of the South coast of India. This phenomenon can be due to nutrient limitation in oligotrophic waters for seaweeds as a result they need to harbour all nutrients in their blades, attracting higher microbial organisms, thus high bioactivity. Secondly the various compounds seaweeds harbour like steroids and phenols also determines their antimicrobial activity, which helps in inhibiting microbial growth by acting on the bacterial cell wall [46] [47].

Our results suggest Gram-positive bacteria ( $S$. aureus) were more susceptible to seaweed extracts than Gram-negative bacteria (E. coli and P. aeruginosa). Similar results have been observed for seaweed extracts against Gram-positive bacteria elsewhere [41] [48]. This difference in response to various seaweed extracts between Gram positive and negative are due to their cell wall structure and chemical composition [42] [49], where Gram negative bacterial species have a thicker outer membrane and murine layer acting as a barrier to many environmental substances and inhibitors and Gram-positive bacteria lacking these features are susceptible to bioactive compounds [50] [51].

This study analysed the bioactive potential of four seaweed species against three common human pathogens through solvent extraction method and observed that $S$. wightii was the most effective seaweed against Gram-positive bacteria $S$. aureus and Gram-negative bacteria $E$. coli and $P$. aeruginosa followed by $G$. edulis and $U$. lactuca, whereas $G$. corticata was the least effective against both Gram positive and negative bacteria. The antimicrobial property exhibited by these seaweeds suggest they have a great potential to be screened for various antibacterial compounds depending on the biochemical composition of red, brown and green seaweeds. This preliminary screening suggests further biochemical characterization of vast source of seaweed secondary metabolities are necessary for discovering new bioactive compounds for various antibacterial drugs to fight against the antibiotics resistance of the $21^{\text {st }}$ century and further.

\section{Acknowledgements}

This work was carried out as summer training internship at San Genomics Research Laboratory, Bangalore, India. I am thankful to Dr. M. P. Prasad for providing laboratory facilities for carrying out the research. I am grateful to Nitya Shree and Sasi Kumar for the helping hands in laboratory works. I am thankful to Anchal Paramguru for her initial comments on the manuscript. 


\section{Conflict of Interest}

The author declares there is no conflict of interest between any organizations for funding or any other reasons.

\section{References}

[1] World Health Organization (WHO) (2017) Antibiotic Resistance, Fact Sheet. http://www.who.int/mediacentre/factsheets/antibiotic-resistance/en/

[2] Bernhoft, A. (2008) A Brief Review on Bioactive Compounds in Plants. The Norwegian Academy of Science and Letters.

[3] Bhadury, P. and Wright, P.C. (2004) Exploitation of Marine Algae: Biogenic Compounds for Potential Antifouling Applications. Planta, 219, 561-578. https://doi.org/10.1007/s00425-004-1307-5

[4] Pérez, M.J., Falqué, E. and Domínguez, H. (2016) Antimicrobial Action of Compounds from Marine Seaweed. Marine Drugs, 14, 52. https://doi.org/10.3390/md14030052

[5] Ravikumar, S., Anburajan, L., Ramanathan, G. and Kaliaperumali, N. (2002) Screening of Seaweed Extracts against Antibiotic Resistant Post-Operative Infectious Pathogens. Seaweed Res. Utilisation, 24, 95-99.

[6] Richard, J.P., Cannell, R.J.P., Owsianka, A.M. and Walker, J.M. (1988) Result of a Large-Scale Screening Programmes to Detect Antibacterial Activity from Fresh Water Algae. British Phycological Journal, 23, 41-44. https://doi.org/10.1080/00071618800650051

[7] Dhargalkar, V.K. and Kavlekar, D. (2004) Seaweeds-A Field Manual. 1st Edition.

[8] Dhargalkar, V.K. and Verlecar, X.N. (2009) Southern Ocean Seaweeds: A Resource for Exploration in Food and Drugs. Aquaculture, 287, 229-242. https://doi.org/10.1016/j.aquaculture.2008.11.013

[9] Pal, A., Kamthania, M.C. and Kumar, A. (2014) Bioactive Compounds and Properties of Seaweeds-A Review. Open Access Library Journal, 1, e752.

[10] Cos, S., Abu-Ghannam, N. and Gupta, S. (2010) An Assessment of the Antioxidant and Antimicrobial Activity of Six Species of Edible Irish Seaweeds. International Food Research Journal, 17, 205-220.

[11] Balboa, E.M., Conde, E., Moure, A., Falqué, E. and Dominguez, H. (2013) In Vitro Antioxidant Properties of Crude Extracts and Compounds from Brown Algae. Food Chemistry, 138, 1764-1785. https://doi.org/10.1016/j.foodchem.2012.11.026

[12] Usov, A.I. (2013) Chemical Structures of Algal Polysaccharides. In: Domínguez, H., Ed., Functional Ingredients from Algae for Foods and Nutraceuticals, Woodhead Publishing, Cambridge, 23-86. https://doi.org/10.1533/9780857098689.1.23

[13] Kumari, P., Kumar, M., Reddy, C.R.K. and Jha, B. (2013) Algal Lipids, Fatty Acids and Sterols. In: Domínguez, H., Ed., Functional Ingredients from Algae for Foods and Nutraceuticals, Woodhead Publishing, Cambridge, 87-134. https://doi.org/10.1533/9780857098689.1.87

[14] Cardoso, M.S., Carvalho, G.L., Silva, J.P., Rodrigues, S.M., Pereira, R.O. and Pereira, L. (2014) Bioproducts from Seaweeds: A Review with Special Focus on the Iberian Peninsula. Current Organic Chemistry, 18, 896-917. https://doi.org/10.2174/138527281807140515154116

[15] Abu-Ghannam, N. and Rajauria, G. (2013) Antimicrobial Activity of Compounds Isolated from Algae. In: Domínguez, H., Ed., Functional Ingredients from Algae for 
Foods and Nutraceuticals, Woodhead Publishing, Cambridge, 287-306. https://doi.org/10.1533/9780857098689.2.287

[16] Singh, R.S., Thakur, S.R. and Bansal, P. (2015) Algal Lectins as Promising Biomolecules for Biomedical Research. Critical Reviews in Microbiology, 41, 77-88. https://doi.org/10.3109/1040841X.2013.798780

[17] Güven, K.S., Percot, A. and Sezik, E. (2010) Alkaloids in Marine Algae. Marine Drugs, 8, 269-284. https://doi.org/10.3390/md8020269

[18] Bedoux, G., Hardouin, K., Burlot, A.S. and Bourgougnon, N. (2014) Bioactive Compounds from Seaweeds: Cosmetic Applications and Future Development. Advances in Botanical Research, 71, 345-379. https://doi.org/10.1016/B978-0-12-408062-1.00012-3

[19] Smit, A.J. (2004) Medicinal and Pharmaceutical Uses of Seaweed Natural Products: A Review. Journal of Applied Phycology, 16, 245-262. https://doi.org/10.1023/B:JAPH.0000047783.36600.ef

[20] Kolanjinathan, K. and Stella, D. (2009) Antibacterial Activity of Marine Macro Algae against Human Pathogens. Recent Research in Science and Technology, 1, 20 22.

[21] Huleihel, M., Ishanu, V., Tal, J. and Shisgaba, A. (2001) Antiviral Effect of Red Microalgal Polysaccharides on Herpes Simplex and Varicella Zoster Virus. Journal of Applied Phycology, 13, 127-134. https://doi.org/10.1023/A:1011178225912

[22] Lee, E.J. and Sung, M.K. (2003) Chemoprevention of Azoxymethane Induced Rat Colon Carcinogenesis by Seatangle, a Fiber-Rich Seaweed. Plant Foods for Human Nutrition, 58, 1-8. https://doi.org/10.1023/B:QUAL.0000040307.57930.a4

[23] Prasad, M.P., Shekhar, S. and Rindhe, G. (2014) Antibacterial Activity of Seaweed (Gracilaria Species) Extracts against Infectious Pathogens. Asian Journal of Biological and Life Sciences, 1, 219-222.

[24] Kolanjinathan, K. and Saranraj, P. (2014) Pharmacological Efficacy of Marine Seaweed Gracilaria edulis Extracts against Clinical Pathogens. Global Journal of Pharmacology, 8, 268-274.

[25] Karthick, P., Mohanraju, R., Narayana Murthy, K. and Ramesh, Ch. (2015) Antibacterial Activity of Seaweeds Collected from South Andaman, India. Journal of Algal Biomass Utilization, 6, 33-36.

[26] Mishra, J.K., Srinivas, T., Madhusudan, T. and Sawhney, S. (2016) Antibacterial Activity of Seaweed Halimeda opuntia from the Coasts of South Andaman. Global Journal of Bioscience and Biotechnology, 3, 345-348.

[27] Ravikumar, S., Anburajan, L. and Balakrishnan, M. (2016) Antibacterial Activity of Ulva reticulata from Southwest Coast of Kanyakumari, India. Journal of Coastal Life Medicine, 4, 246-247. https://doi.org/10.12980/jclm.4.2016j5-66

[28] Alang, G., Kaur, R., Singh, A., Budlakoti, P., Singh, A. and Singla, P. (2009) Antimicrobial Activity of Ulva lactuca Extracts and Its Fractions. Pharmacology Online, 3, 107-117.

[29] Deveau, A.M., Miller-Hope, Z., Lloyd, E., Williams, B.S., Bolduc, C., Meader, J.M., Weiss, F. and Burkholder, K.M. (2016) Antimicrobial Activity of Extracts from Macroalgae Ulva lactuca against Clinically Important Staphylococci Is Impacted by Lunar Phase of Macroalgae Harvest. Letters in Applied Microbiology, 62, 363-371. https://doi.org/10.1111/lam.12563

[30] Kolanjinathan, K. and Stella, D. (2011) Comparative Studies on Antimicrobial Activity of Ulva reticulata and Ulva lactuca against Human Pathogens. International 
Journal of Pharma and Bio Sciences, 6, 1738-1744.

[31] Thirumalairaj, V.K., Vijayan, M.P., Durairaj, G., Shanmu-gaasokan, L., Yesudas, R. and Gunasekaran, S. (2014) Potential Antibacterial Activity of Crude Extracts and Silver Nanoparticles Synthesized from Sargassum wightii. International Current Pharmaceutical Journal, 3, 322-325. https://doi.org/10.3329/icpj.v3i10.20337

[32] Vijayabaskar, P. and Shiyamala, V. (2011) Antibacterial Activities of Brown Marine Algae (Sargassum wightii and Turbinaria ornata) from the Gulf of Mannar Biosphere Reserve. Advances in Biological Research, 2, 99-102.

[33] Chandrasekaran, M., Venkatesalu, V., Adaikala, R. and Krishnamoorthy, S. (2014) Antibacterial Properties of Various Extracts of Sargassum wightii against Multidrug Resistant Bacterial Strains. Phykos, 44, 17-28.

[34] Fayaz, M., Namitha, K.K., Murhty, K.N., Swamy, M.M., Sarada, R., Khanam, S., Subbarao, P.V. and Ravishankar, G.A. (2005) Chemical Composition, Iron Bioavailability and Antioxidant Activity of Kappaphycus alvarezzi (Doty). Journal of Agricultural and Food Chemistry, 53, 729-797. https://doi.org/10.1021/jf0493627

[35] Elloff, J.N. (1998) A Sensitive and Quick Microplate Method to Determine the Minimal Inhibitory Concentration of Plant Extracts for Bacteria. Planta Medica, 64, 711-713. https://doi.org/10.1055/s-2006-957563

[36] Jeyachandran, R., Baskaran, X. and Cinderella, L. (2010) Screening of Phytochemical and Antibacterial Potential of Four Indian Medicinal Plants. Libyan Agriculture Research Center Journal International, 5, 301-306.

[37] Subba Rangaiah, G., Lakshmi, P. and Manjula, E. (2010) Antimicrobial Activity of Seaweeds Gracillaria, Padina and Sargassum sp. on Clinical and Phytopathogens. International Journal of Chemical and Analytical Science, 1, 114-117.

[38] Salvador, N., Gomez Garreta, A., Lavelli, L. and Ribera, M.A. (2007) Antimicrobial Activity of Iberian Macroalgae. Scientia Marina, 71, 101-113.

https://doi.org/10.3989/scimar.2007.71n1101

[39] Gonzalez Del Val, A., Platas, G., Basilio, A., Cabello, A., Gorrochategui, J., Suay, I., Vicente, F., Portillo, E., Jiménez Del Rio, M., Reina, G.G. and Pelaez, F. (2001) Screening of Antimicrobial Activities in Red, Green and Brown Macroalgae from Gran Canaria (Canary Islands, Spain). International Microbiology, 4, 35-40.

[40] Karabay-Yavasoglu, N.U., Sukatar, A., Ozdemir, G. and Horzum, Z. (2007) Antimicrobial Activity of Volatile Components and Various Extracts of the Red Alga Jania rubens. Phytology Research, 21, 153-156. https://doi.org/10.1002/ptr.2045

[41] Taskin, E. and Ozturk Kurt, M. (2001) Antibacterial Activities of Some Marine Algae from the Aegean Sea (Turkey). African Journal of Biotechnology, 6, 2746-2751.

[42] Kandhasamy, M. and Arunachalam, K.D. (2008) Evaluation of in Vitro Antibacterial Property of Seaweeds of Southeast Coast of India. African Journal of Biotechnology, 12, 1958-1961.

[43] Ibtissam, C., Radio, H., Martinez-Lopez, J., Dominguez, S.J.F., Gomez, V.J.A. and Bouziane, H. (2009) Screening of Antibacterial Activity in Marine Green Brown Macroalgae from the Coast of Morocco. African Journal of Biotechnology, 8, 1258 1262.

[44] Balasankar, T. and Pushparaj, A. (2014) Antimicrobial Activity of Red Seaweed Gracilaria corticata against Human Pathogenic Bacterial Strains. World Journal of Pharmaceutical Sciences, 2, 1901-1904.

[45] Zubia, M., Payri, C. and Deslandes, E. (2008) Alginate, Mannitol, Phenolic Compounds and Biological Activities of Two Range-Extending Brown Algae, Sargassum 
mangarevense and Turbinaria ornata (Phaeophyta: Fucales), from Tahiti French Polynesia. Journal of Applied Phycology, 20, 1033-1043.

https://doi.org/10.1007/s10811-007-9303-3

[46] Raquel, F. and Epand, F. (2007) Bacterial Lipid Composition and the Antimicrobial Efficacy of Cationic Steroid Compounds. Biochimica et Biophysica Acta, 1768, 2500-2509.

[47] Reguant, C., Bordons, A. and Arola Roze, N. (2000) Influence of Phenolic Compounds on the Physiology of Oenococcus oeni. Journal of Applied Microbiology, 88, 1065-1071. https://doi.org/10.1046/j.1365-2672.2000.01075.x

[48] Tuney, I.B., Cadirci, H., Unal, D. and Sukatar, A. (2006) Antimicrobial Activities of the Extracts of Marine Algae from the Coast of Urla (Turkey). Turkish Journal of Biology, 30, 1-5.

[49] Paz, E.A., Lacy, R.N. and Bakhtian, M. (1995) The B-Lactum Antibiotics Penicillin and Cephalosporin in Perspective. Hodder Strong, London, 324.

[50] Martin, G.J. (1995) Ethnobotany: A Methods Manual. Chapman \& Hall, London. https://doi.org/10.1007/978-1-4615-2496-0

[51] Tortora, G.J., Funke, C.L. and Case, B.R. (2001) Microbiology: An Introduction. Benjamin Cummings, San Francisco, 88. 